\title{
ВОДОЗАБОРНАЯ СКВАЖИНА КАК ОБЪЕКТ НЕДВИЖИМОСТИ
}

\section{Шамиль Анварович Истислямов}

Сибирский государственный университет геосистем и технологий, 630108, Россия, г. Новосибирск, ул. Плахотного, 10, обучающийся, тел. (999)451-71-50, e-mail: istislyamov.sh@mail.ru

В статье рассматривается вопрос определения такого специфического объекта недвижимости как водозаборная скважина. Цель: определить статус объекта и отношение водозаборной скважины к движимой и недвижимой вещи. Также рассмотрены особенности водозаборной скважины как объекта недвижимости.

Ключевые слова: объект недвижимости, движимая и недвижимая вещь, скважина, водозабор, зона с особым условием использования территории, зона санитарной охраны

\section{WATER INTAKE WELL AS A REAL ESTATE OBJECT}

\section{Shamil A. Istislyamov}

Siberian State University of Geosystems and Technologies, 10, Plakhotnogo St., Novosibirsk, 630108, Russia, Student, phone: (999)451-71-50, e-mail: istislyamov.sh@mail.ru

The article discusses the issue of defining such a specific real estate object as a water intake well. The purpose of the paper is to determine the status of the object and the relation of the water intake well to movable and immovable things. The features of a water intake well as a real estate object are also considered.

Keywords: real estate object, movable and immovable property, well, water intake, zone with a special condition for using the territory, sanitary protection zone

Определение объекта как недвижимого имущества создает социальный, технический и правовой подход к нему. В отличие от «движимости», недвижимость для человека имеет высокую ценность. Особенность недвижимой вещи (недвижимости), заключается в специальном порядке возникновения права на недвижимую вещь, путем сделки с недвижимостью, а также все регистрационные и учетные действия в отношении данной недвижимости. В результате учетно-регистрационных действий вещь признается недвижимой в правовом поле. Регистрационные действия позволяют закрепить права субъекта над недвижимым объектом. Таким образом, недвижимость является ключевым элементом вещного права (совокупности норм, которые регулируют господство над своей или чужой как движимой, так и недвижимой вещью) [1]. При этом понятие «недвижимость» или «недвижимая вещь» в Российском праве неоднозначно. Границы того, что является недвижимостью, а что нет, остаются размытыми несмотря на систематические попытки определить принадлежность вещи к группе «движимости» или недвижимости. 
Цель данной статьи заключается в том, чтобы выявить, особенности водозаборной скважины как объекта недвижимости.

Для достижения поставленной цели, необходимо решить следующие задачи:

- выяснить, что является объектом недвижимости в законодательной сфере (в теории) и на практике;

- определить, какие виды объектов могут относиться к категории недвижимости;

- выявить зависимость одних объектов недвижимости от других;

- изучить особенности водозаборной скважины и определить, является ли она объектом недвижимости.

Если рассматривать объект недвижимости с физической точки зрения, то его недвижимость заканчивается тогда, когда мы говорим о его возможности перемещения, основываясь на правиле, что движимостью признаются объекты, которые не являются недвижимостью [1].

Что касаемо правовой стороны вопроса недвижимости, в статье 130 Гражданского кодекса Российской Федерации поясняется, что к недвижимым вещам (недвижимости) относятся объекты, переместить которые без несоразмерного ущерба их назначению не представляется возможным. Это земельные участки, участки недр, здания, сооружения, объекты незавершенного строительства [2]. Кроме того, к недвижимым вещам закон относит морские и воздушные суда, суда внутреннего плаванья (речные), которые подлежат государственной регистрации. Также отмечается, что к недвижимым вещам может быть отнесено иное имущество.

Значимость разделения движимых вещей от недвижимых заключается в ценности, функциональных свойствах одних объектов гражданского права от других. Как правило, недвижимые вещи в большинстве своем, находятся в постоянном покое, в то время как движимые вещи, перемещаются вместе с лицами, обладающими данными вещами [3].

Законодательство РФ разделяет земельный участок и объект капитального строительства друг от друга, как разные объекты недвижимости. При этом с правовой стороны, одно невозможно без другого. Мы не можем построить дом, не имея под ним основания - земельный участок. В этом случае существует принцип единства объекта капитального строительства и земельного участка, как одного целого.

По мнению Бевзенко Р.С. [1], современное отношение к пониманию недвижимости имеет существенный недостаток. Проблема возникает в том, что законодательство относит к понятию недвижимости те объекты, которые возможно перемещать. И осознание того, что переместить в реальности можно практически любой объект приводит к противоречию понимания недвижимости. В качестве примера можно привести распространенный случай, когда землевладельцы регистрируют право собственности на сборно-разборный деревянный дом. В результате регистрируя права собственности на недвижимость, ничего не препятствует тому, чтобы разобрать и перевезти объект недвижимости в другое место. 
Еще более интересный вопрос, является ли объектом недвижимости, подземные коммуникации, асфальтовое покрытие или скажем капитальный забор из кирпича [1].

Если исходить из российского законодательства, то такие объекты тоже являются недвижимыми, потому что на практике существуют случаи, когда субъекты регистрировали права на такие объекты недвижимости.

С юридической точки зрения, например, асфальтовое покрытие или забор само по себе ценности не имеет, а приобретает ее лишь тогда, когда становится частью земельного участка. И с юридической точки зрения такие объекты как подземный трубопровод, забор, асфальтовое покрытие не является объектом недвижимости, а лишь составной частью земельного участка. Исходя из западной концепции, законодатель не может точно и корректно определить, что является объектом недвижимости, в результате признает в качестве недвижимости только земельный участок, а любые виды объектов капитального строительства не как самостоятельный вид объекта недвижимости, а продолжение земельного участка (составная часть). Подобный подход является наиболее простым и практичным и склоняется к тому, что достаточно быть владельцем земельного участка, и ты сам решаешь, что ты будешь на нем возводить и что делать [1].

Однако в практике российского законодательства все объекты капитального строительства на земельном участке относятся к категории недвижимых вещей. Но при этом, лицо, которое обращается в уполномоченный орган за регистрацией права на такую недвижимою вещь, как объект капитального строительства, предварительно должно зарегистрировать права на земельный участок.

Главный вопрос, на который автор стремится ответить в данной статье, заключается в том, чтобы понять, к какой категории относится водозаборная скважина или просто скважина.

На практике, скважина - это образование отверстия, в виде круглого сечения, содержащие в себе обсадную трубку, берущую начало с поверхности земли и уходящую в глубь недр при помощи бурового оборудования (рис. 1).

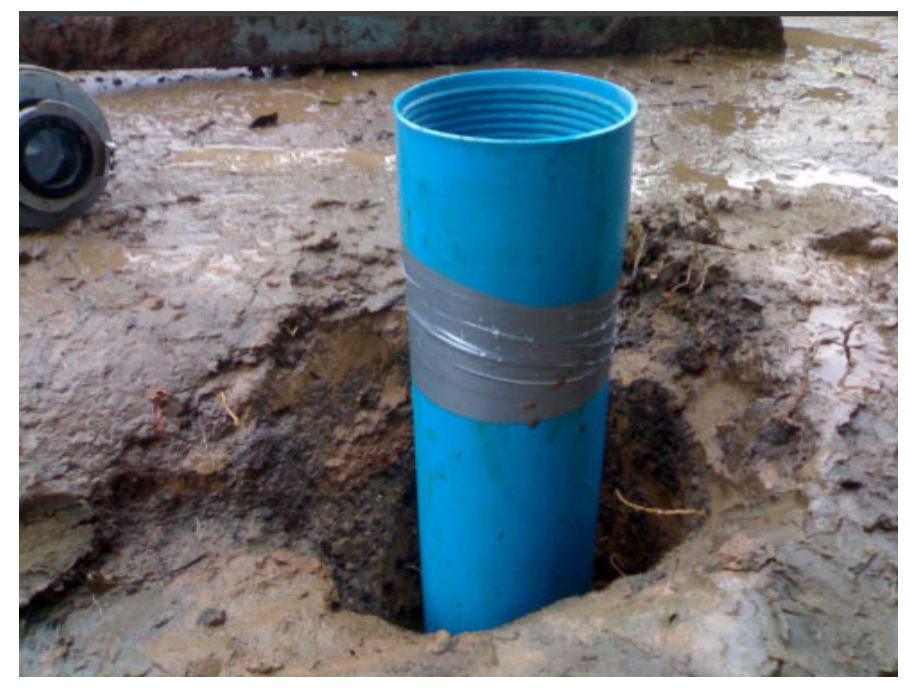

Рис. 1. Пример скважины 
С одной стороны, наиболее логичным является отнесение скважины к понятию составной части земельного участка, так как она расположена в границах земельного участка. Но в действительности в отношении скважины все намного серьезнее. Исходя из ст. 130 Гражданского кодекса Российской Федерации участки недр являются недвижимостью [2]. В ходе бурения скважины затрагиваются недра земли. Согласно Закона Российской Федерации от 21.02.1992 № 2395-1 «О недрах» [4], все недра принадлежат государству (Российской Федерации), но при этом законодательство выделяет отдельный объект недвижимости - участки недр. Возникает вопрос, относится ли скважина к объекту недвижимости, если учесть, что она большей частью своей располагается вне земельного участка, а в недрах государственной собственности и одновременно имеет свои индивидуально-определенные характеристики, пользу из которых извлекает всякий собственник или землепользователь земельного участка. Подобная ситуация напоминает собой сервитут обращенный в пользу землевладельца или землепользователя со стороны государства [8]. Стоит отметить что в статье 19 Закона Российской Федерации «О недрах» за владельцами участков закреплено право использования общедоступных недр, в том числе подземных вод [4]. Однако использование данных недр должно осуществляется в соответствии со статьей 11 того же закона, в которой указано правомерное использование участком недр в виде оформления специального государственного разрешения - лицензии [4].

Получается, если лицо планирует строительство, например, жилого дома, то ему достаточно иметь право на земельный участок. А в случае со скважиной ему необходимо иметь как право на земельный участок, так и право на пользование под скважиной участком недр. Так как земельный участок предполагает почвенный слой или поверхность земли, в то время, как, то, что ниже земельного участка, является недрами.

В отличие от всех других видов объектов недвижимости, скважина имеет такую характеристику как глубину залегания. И данная характеристика также может повлиять на определение скважины как объекта недвижимости. Чтобы это понять, нужно изучить разновидности подземных водных источников.

Подземные воды располагаются в толще земной коры, в различных физических состояниях. В ходе водоснабжения затрагиваются свободные воды, которые заполняют поры фильтрующих грунтов и передвигающиеся по действием силы тяжести (рис. 2) [6].

Подземные источники водоснабжения имеют несколько вариантов глубины залегания, от которых зависят качественные характеристики добываемой воды. Сюда входят следующие подземные воды:

- верховодка;

- грунтовые воды;

- артезианские воды. 


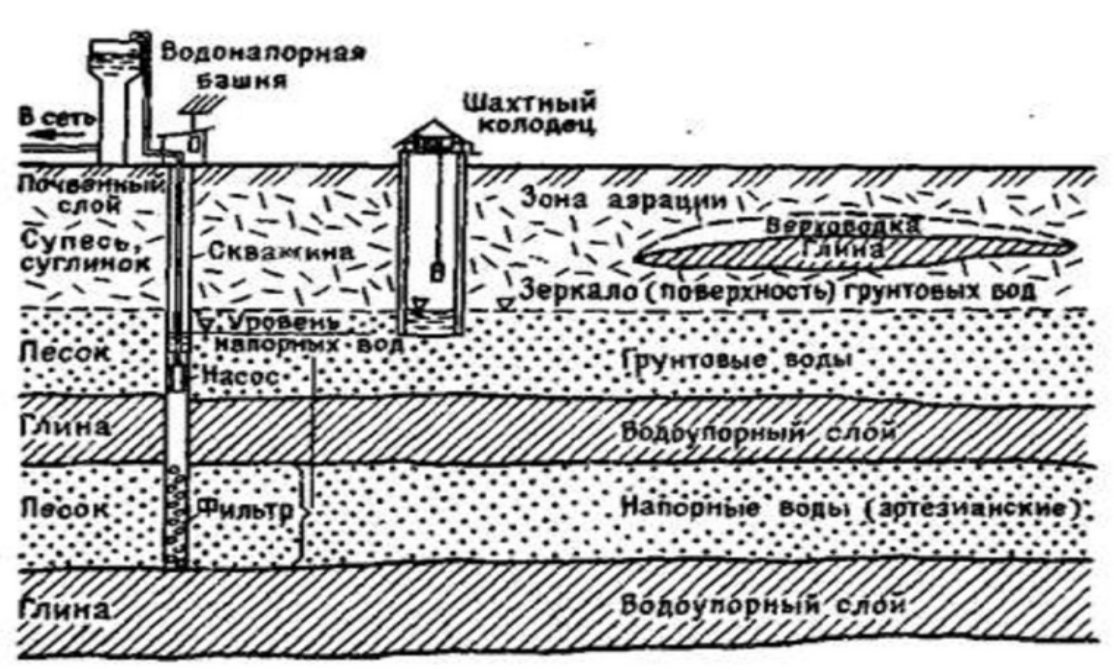

Рис. 2. Схема глубинного расположения подземных водных источников

Верховодкой называют скопления водных масс в результате осадков (проникающих в почву), сконцентрированных на небольшой глубине от поверхности земли в зоне аэрации [6]. Для забора воды из верховодки достаточно небольшой глубины до 10 метров. У водозабора организованного на глубине верховодки низкая производительность, как правило не более 500 литров в час (также зависит от времени года). Ресурс использования водозабора из верховодки не более 5-10 лет. вода из верховодки не предназначена для питья. Такую воду можно использовать исключительно для ведения хозяйственных нужд.

Грунтовые воды - это безнапорные или с местным напором воды, которые залегают на небольших глубинах, имеют сток (стекание в реки). Грунтовые воды характеризуются большим запасом воды. В большинстве случаев они не зависят от осадков, обеспечены защитой от попадания загрязнения с поверхности земли и характеризуются наиболее стабильной температурой в течении года и сохранением уровня. Грунтовые воды наиболее часто используют для централизованного водоснабжения населенных пунктов [6]. Залегают грунтовые воды на глубине от 20 до 50 метров. Несмотря на то, что грунтовые воды значительно чище вод верховодки, добыча такой воды полагается с использованием водоочистительных систем и контроля качества, так как она может содержать примеси.

Артезианские воды - это подземные воды, находящиеся под напором, на достаточно значительной глубине между водонепроницаемыми пластами, заполняющие или циркулирующие в трещинах породы. За счет водонепроницаемых пород, вода в таких слоях надежно защищена от поверхностных стоков. Запасы артезианской воды значительны и устойчивы, имеют постоянную температуру и кроме того насыщены минералами и не имеет никаких вредных примесей. Артезианские пресные воды являются самыми предпочтительными для целей централизованного хозяйственно-питьевого водоснабжения населенных пунктов 
[6]. Глубина залегания чистых потоков артезианских вод начинается с 50 метров и более. Это самый чистый и надежный вид воды с точки зрения санитарных требований.

Существует несколько типов водозаборных устройств. Это могут быть и шахтные колодцы (до 30 метров), горизонтальные водозаборы (до 10 метров), лучевые водозаборы (до 15-20 метров), предназначенные преимущественно для временной слабо напорной и небольшой производительности. Но наиболее надежным и распространенным типом водозаборного устройства является скважина. Скважину можно применять в различных условиях для добычи подземных вод из водоносных пластов с большой мощностью и глубиной залегания от 10 до 1000 метров.

Однако, в статье 19 закона Российской Федерации от 21.02.1992 № 2395-1 (ред. от 27.12.2019) «О недрах» за владельцами участков закреплено право использования общедоступных недр, в том числе подземных вод. Владельцы могут добывать воду из скважины случаях, представленных на рис. 3 [4].

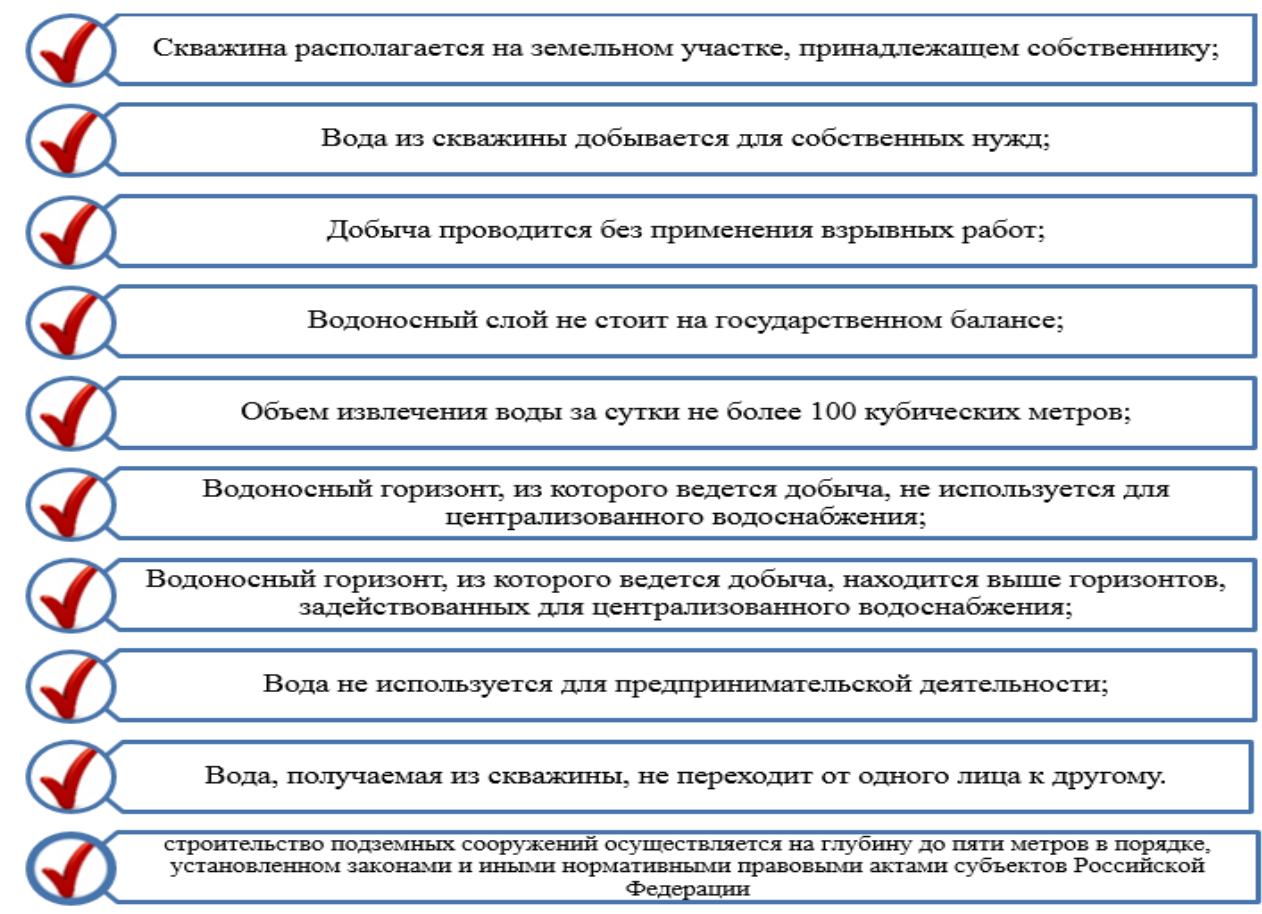

Рис. 3. Случаи, при которых землевладельцы и землепользователи имеют право использовать общедоступные недра без получения лицензии

Из этого следует что по общему правилу для эксплуатации скважины необходимо получение лицензии. Но в случаях, приведенных на рисунке 3 , собственник земельного участка может использовать такой источник водоснабжения без получения лицензии на пользование недрами [5].

Так как законодатель выделяет участки недр как отдельный вид объекта недвижимости, значит, принимая решение установить скважину, землепользователь или собственник должен учитывать алгоритм зависимости одного объекта 
от другого (рис. 4). Чтобы установить скважину, необходим не только земельный участок, но и право на пользование недрами.

Чтобы можно было отнести скважину к объекту недвижимости с правовой точки зрения, необходимо обеспечить такую основу для скважины, как земельный участок и участок недр. Участки недр в соответствии со ст. 7 закона Российской Федерации «О недрах» предоставляются для пользования в виде горного отвода - геометризованного блока недр [4].

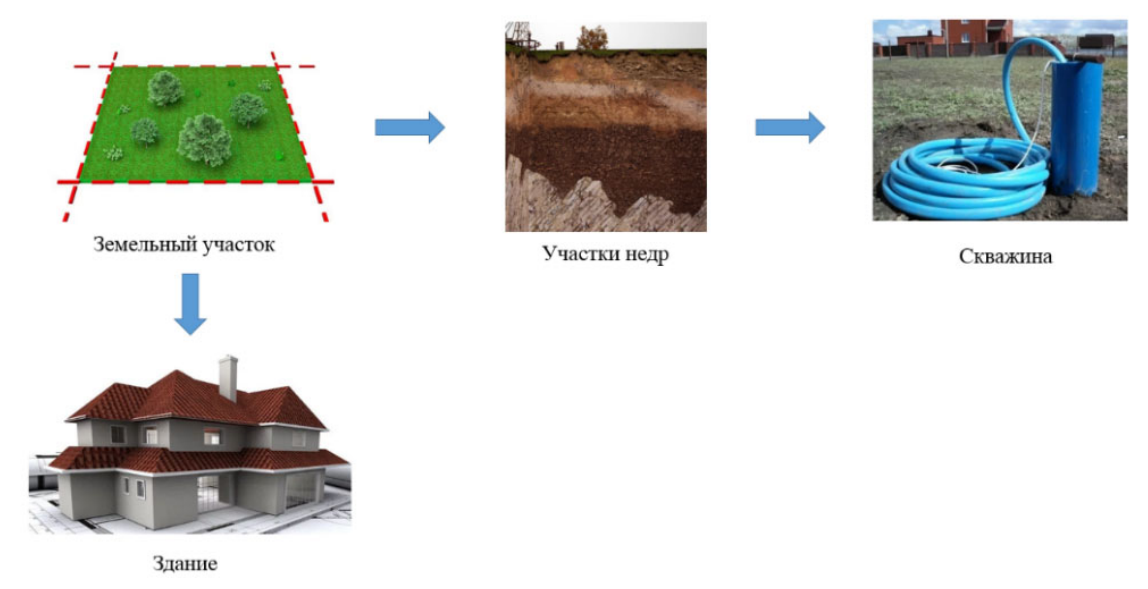

Рис. 4. Зависимость одних объектов недвижимости от других

Согласно теории Бевзенко Р.С. [1], объекты капитального строительства, такие как здания, сооружения, и другие виды недвижимости, расположенные в границах земельного участка одного и того же собственника, можно отнести к единому целому по принципу: ОКС составная часть земельного участка, то скважина является составной частью как земельного участка, так и участка недр. Только в комплексе «земельный участок, участок недр и скважина» водозабор можно назвать объектом недвижимости.

Делая вывод из вышеописанного, можно однозначно говорить о том, что скважина является объектом недвижимости. Потому что она подходит под определение недвижимости определяемое законодателем. Ее можно отнести к недвижимой вещи перемещение которой невозможно без несоразмерного ущерба назначению данной вещи. Кроме того, недра являются ключевым элементом водозаборной скважины и сам водозабор имеет непосредственную связь с водоносным горизонтом, что требует пристального внимания к себе как к объекту недвижимости.

Необходимо выделить тот факт, что водозаборная скважина, как объект недвижимости, в отличие от здания, в соответствии с СанПин 2.1.4.1110-02, в обязательном порядке должна иметь в отношении себя зону санитарной охраны источников питьевого и хозяйственно бытового водоснабжения (3СО) [7]. А это один из видов зон с особым условием использования территории (ЗОУИТ). Таким образом, водозаборная скважина, являясь объектом недвижимости, в ходе 
осуществления государственного кадастрового учета и регистрации прав, должна быть обеспечена проектом 3СО, который направлен на защиту водозабора от микробного и химического загрязнения. Нужно понимать, что ЗСО обременяет другие, рядом находящиеся объекты недвижимости, и возлагает на землевладельцев в подобной зоне ответственность.

По мнению автора, образование ЗСО является одним из критериев признания водозаборной скважины объектом недвижимости. Когда для объекта определяется 3СО, фактически подчеркивается его значимость и высокая социальная ценность. Делается это для того, чтобы защитить водоносный горизонт от вероятного попадания вредных элементов, что угрожает здоровью и благополучию населения.

Таким образом, необходимо признать особенность и степень важности артезианских и грунтовых скважин в отличие от скважин верховодки и всех других видов объектов недвижимости, как сооружения имеющего доступ к общественному источнику питьевой воды.

\section{БИБЛИОГРАФИЧЕСКИЙ СПИСОК}

1. Бевзенко Р.С.Б 36 Земельный участок с постройками на нем: введение в российское право недвижимости [Электронное издание]. - М.: М-Логос, 2017. - 80 с.

2. Гражданский кодекс Российской Федерации (часть первая) от 30.11.1994 №51-Ф3.

3. Движимое и недвижимое имущество: виды и различия. Электронный ресурс: [https://www.dp.ru/a/2011/06/07/Dvizhimoe_i_nedvizhimoe_imu].

4. Закон Российской Федерации от 21.02 .1992 N 2395-1 (ред. от 27.12.2019) «О недрах».

5. Карпик А.П., Федоренко Ю. В., Пархоменко Д. В. О роли геоинформации в решении гражданско-правовых проблем Единого государственного реестра недвижимости (на материалах Иркутской области) // Вестник СГУГиТ. - 2017. - №2(38). С. 154-170.

6. Курганов, А. М., Вуглинская, Е. Э. Водозаборы подземных вод: учеб. пособие для студентов специальности 270112 - водоснабжение и водоотведение всех форм обучения /А. М. Курганов, Е. Э. Вуглинская; СПбГАСУ. - СПб., 2009. - 80 с.

7. О введении в действие санитарных правил и норм «зоны санитарной охраны источников водоснабжения и водопроводов питьевого назначения СанПин 2.1.4.1110-02»: Постановление Главного государственного санитарного врача РФ от 14 марта 2002 г. № 10.

8. Пархоменко Д. В., Предтеченская Е. А. Правовой и геоинформационный аспекты публичных сервитутов в Российской Федерации // Вестник СГУГиТ. - 2019. - Том 24 (2). С. 205-219.

(С) Ш. А. Истислямов, 2021 